Techniques \& Culture

\title{
À Robert Cresswell, (1922-2016)
}

Frédéric Joulian

\section{(2) OpenEdition}

Journals

Édition électronique

URL : https://journals.openedition.org/tc/7769

DOI : $10.4000 /$ tc. 7769

ISSN : 1952-420X

\section{Éditeur}

Éditions de l'EHESS

\section{Édition imprimée}

Date de publication : 31 octobre 2016

Pagination : 8-9

ISBN : 9782713225291

ISSN : 0248-6016

\section{Référence électronique}

Frédéric Joulian, « À Robert Cresswell, (1922-2016) », Techniques \& Culture [En ligne], 65-66 | 2016, mis en ligne le 31 octobre 2019, consulté le 29 septembre 2022. URL : http://journals.openedition.org/tc/ 7769 ; DOI : https://doi.org/10.4000/tc.7769 


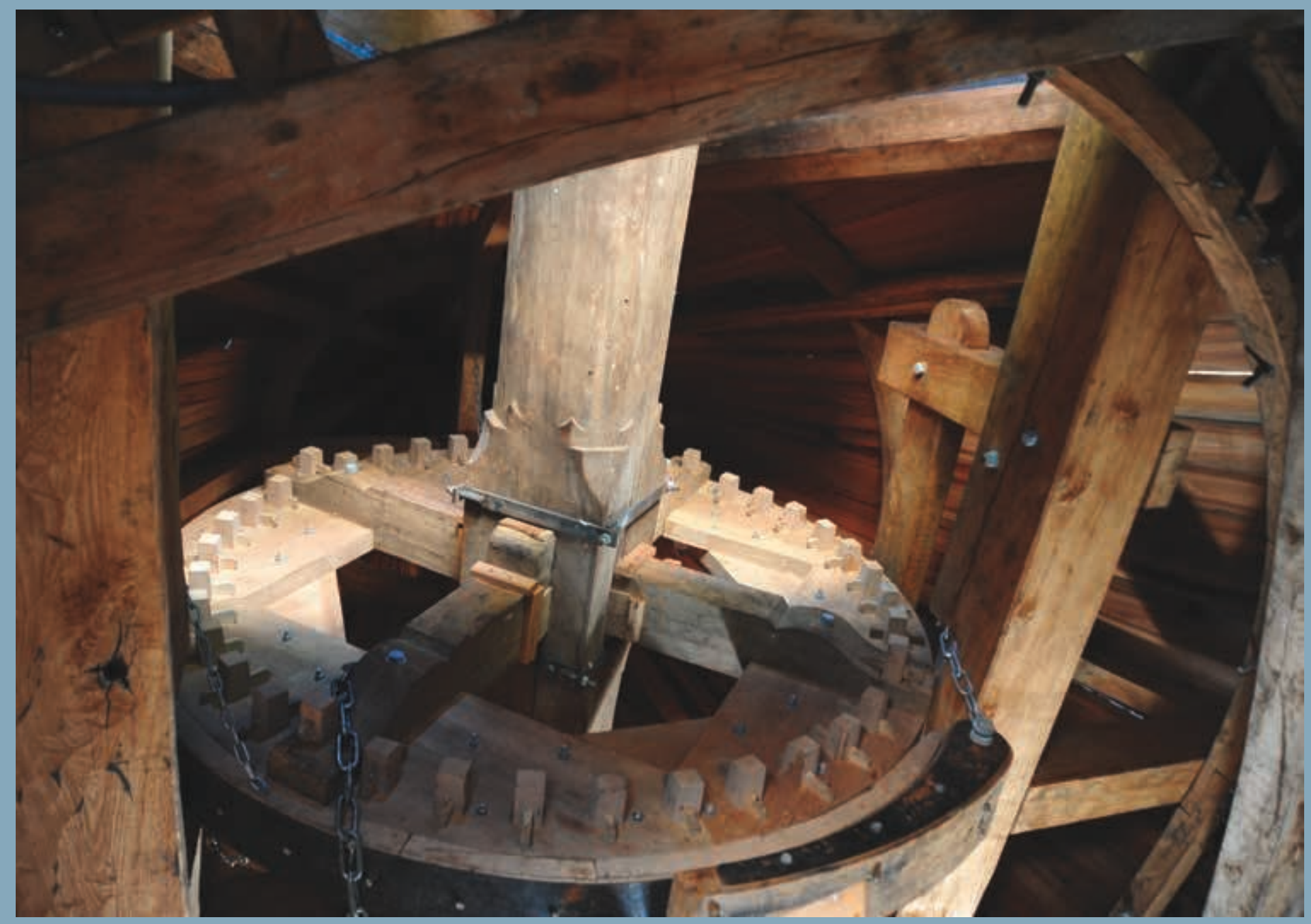




\section{À Robert Cresswell,}

(1922-2016)

Nous souhaitons dédier ce volume à Robert Cresswell et le remercier de façon posthume d'avoir si bien su lancer et encourager un mouvement de groupe, d'avoir instillé la passion de la recherche, celle des «techniques en société», des terrains comparés et des débats collectifs (ci-dessous à l'occasion des 35 ans de la revue au musée du quai Branly), au fil des aventures administrativo-scientifiques d'une équipe qu'il créa de toutes pièces et des séminaires qu'il anima à Paris V, au CNRS à Ivry ou à la Maison des sciences de l'homme.

À son exigence de ne pas dissocier les sociétés humaines en évolution et en extension (son héritage leroi-gourhanien), les formules sociales dans leur localité ou leur généralité, le lowtech du high-tech, le structuralisme du marxisme et de la technologie culturelle... la nouvelle génération de Techniques\& Culture a emboîté le pas de façon enthousiaste et a dessiné à sa suite de nouvelles pistes de recherches.

Merci à Bob et à ses collègues et amis (François Sigaut, Martine Cresswell, François-René Picon, Jean-Luc Jamard, Madeleine Akrich, Salvatore D'Onofrio, Marie-Noëlle Chamoux, MarieClaude Mahias, Pierre Lemonnier, ... pour n'en citer que quelques-uns) d'avoir accepté le changement en même temps qu'une certaine continuité... Merci de nous avoir permis d'étendre l'exploration anthropologique et les écritures du terrain.

Puissent sa curiosité, son humour et son exigence continuer de veiller encore longtemps sur le réseau TechniquesEC Culture. À l'image d'un jeune homme débarqué en France en juin 1944, émerveillé d'explorer et d'étudier l'«Ancien Monde».

Frédéric Joulian

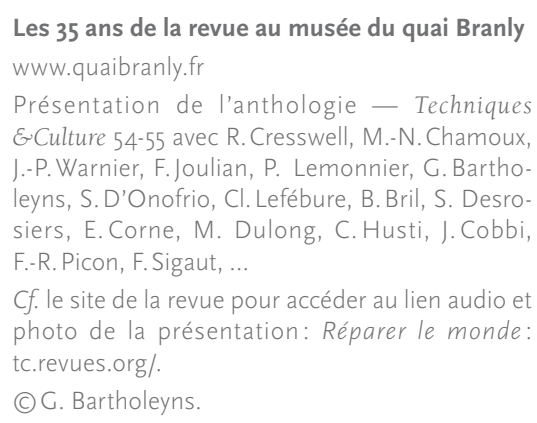

$C f$. le site de la revue pour accéder au lien audio et photo de la présentation: Réparer le monde. tc.revues.org/.

(C) G. Bartholeyns.

En ouverture: Moulins de Paillas, Ramatuelle (C) F. Joulian.

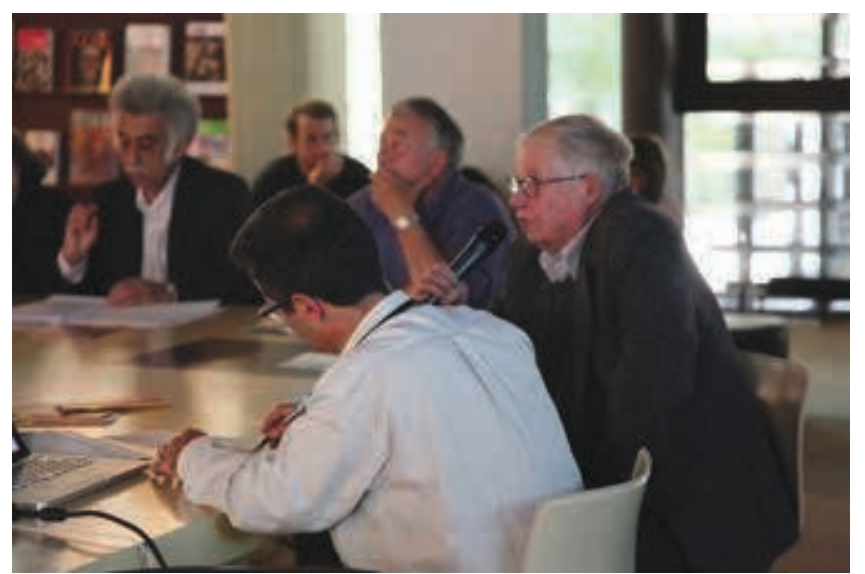

